\title{
EVALUATING THE EFFICACY OF A BIOFEEDBACK \\ INTERVENTION TO REDUCE CHILDREN'S ANXIETY
}

L. STANLEY WENCK

Ball State University
PATRICIA WORK LEU

University of South Dakota

RIK CARL D'AMATO

University of Northern Colorado

\begin{abstract}
This study explored the reduction of anxiety with children using a combination of electromyograph and thermal biofeedback techniques. One hundred and fifty children (7th and 8th graders) were identified by teachers as anxious and randomly assigned to biofeedback intervention and no-intervention groups. Biofeedback intervention subjects received 6 sessions of thermal training and 6 sessions of electromyographic training over a 6 week period. A post-test anxiety scale demonstrated a significant reduction in both state and trait anxiety. This study suggested biofeedback as a viable intervention which might be coordinated and provided by psychologists to reduce anxiety in children. (C) 1996 John Wiley \& Sons, Inc.
\end{abstract}

For many children, life is a daily confrontation with tension and failure (Sonuga-Barke \& Balding, 1993). Family and academic demands combine with changing developmental and social pressures to create an environment in which effective functioning may be difficult. Although anxiety has been shown to have a negative effect on the general health and performance of children, a large number of children face life each day unaware that their symptoms may have solutions (Lail \& Schroeder, 1990).

Given these difficulties, numerous authors have called for psychologists to increase intervention services (D'Amato \& Rothlisberg, 1992; Kratochwill \& Morris, 1991; Sandoval, 1988). Traditionally, psychologists are often called upon to assist children with the broad array of anxiety associated problems which are often concomitant with societal and school difficulties (D'Amato \& Dean, 1989). Unfortunately, the array of interventions shown to be effective experimentally is often limited. Therefore, this research was conducted to determine the efficacy of a biofeedback intervention in the reduction of children's anxiety.

Since behavior is biologically related, it is logical to pair biological functions with behavior to illicit change (Hynd \& Willis 1988; Pliszka, Hatch, Borcherding, \& Rogness, 1993; Whitten, D'Amato, \& Chittooran, 1992). One methodology, biofeedback, combines behavior with biological responses and has shown promise. Yet it has often been delegated to a medical setting (Hatch, Prihoda, \& Moore, 1992; Orton \& Noonberg, 1980). By limiting the use of biofeedback to a medical setting, the benefits are obviously restricted. A logical alternative would be to utilize the procedure in public school settings where children and anxiety are both abundantly available.

Biofeedback may be described as the process of providing information about an ongoing physical response in the body. This knowledge then, is used to change the bodily response and thus increase self control and decrease the anxiety symptoms (Orton \& Noonberg, 1980 ). The procedure provides information to the trainee about bodily reactions (i.e., anxi-

\footnotetext{
This research was supported by Indiana Department of Public Instruction ESEA Title IV-C, Division of Innovative Education Project \#24-76-0453-2.

For additional information contact: Rik Carl D'Amato, PhD., Director, Programs in School Psychology, Division of Professional Psychology, McKee Hall 248, University of Northern Colorado, Greeley, CO 80631.
} 
ety produced responses) such as muscle tension. By learning to control the anxiety reaction in the body, symptoms such as cold hands or test anxiety can be alleviated. This occurs because the cycle of anxiety is broken (Orton \& Noonberg, 1980).

Anxiety has been defined as a general discomfort concerning upcoming events in concert with an inability to control the situation (Schalling, 1977; Spielberger, 1977). Clearly, this describes the reality of many children in any group setting. For clarity, Spielberger (1977) has refined the concept of anxiety by identifying state and trait anxiety. State anxiety is seen as anxiety which is transient while trait anxiety is seen as an intrinsic and lasting reaction to the child's world. Researchers have suggested that children's anxiety responses can be understood as an array of generalized behavioral and physiological reactions (Boyle, 1987; Morris \& Morris, 1992). Generalized anxiety detrimentally affects learning by impeding the acquisition of new knowledge and impairing the retrieval of previously learned material. Additionally, it may restrict short term memory, depress social and school performance, and impede test performance. Physiologically, anxiety has been associated with symptoms such as tension headaches, elevated blood pressure, asthma and cold hands (Culler \& Hollahan, 1980; Gross \& Mastenbrook, 1980; King \& Ollendick, 1989; Lail \& Schroeder, 1990; Smith \& Womack, 1987).

Biofeedback has been shown to be a viable intervention which might be used to assist children in any school or group setting. Its successful use has been established with numerous adults and small groups of children in medical settings. For example, biofeedback procedures were able to significantly increase the self concept of elementary age children (Wenck $\&$ Worster, 1978). In a research review, Chang and Hiebert (1989) concluded biofeedback to be effective in reducing test anxiety, lowering anxiety in hyperactive children, and in decreasing physiological symptoms.

The reduction of both state and trait anxiety was investigated by Roome and Romney (1985) with a group of 30 children. Three groups of 10 children were assigned to Electromyograph (EMG) biofeedback, Progressive Muscle Relaxation (PMR) biofeedback, or a no-treatment group. Both biofeedback groups were able to significantly reduce state anxiety. In another study designed to reduce the anxiousness of children prior to competition, biofeedback was applied to precompetitive anxiety in 20, high trait-anxious males (ages 10 to 13) involved in bogus competitive athletic events. In this study, electromyograph biofeedback techniques were significantly effective in relaxing the identified target muscle (Blais \& Vallerand, 1986). More recently, Potashkin and Beckles (1990) demonstrated the effectiveness of Electromyograph (EMG) biofeedback over Ritilan alone in reducing muscle tension, increasing relaxation, and reducing hyperactivity in a group of 18 males ages 10 to 13 labeled as Attention Deficit Hyperactive Disordered (ADHD).

While these studies have established biofeedback as an efficacious methodology with ADHD children and children involved in athletics, the feasibility and significance of biofeedback when used with a large sample of children within a public school setting has not been established.

\section{MethoD}

\section{Subjects}

After providing teachers with a behavioral description of anxiety, approximately 300 7 th and 8th grade students were nominated as possessing greater than average levels of anxiety. In an effort to validate anxiety levels, the IPAT Anxiety Scale (Cattell \& Scheier, 1976) was administered to all students in this group. This is a 40 question, self-report scale which measures covert and overt anxiety with 20 questions for each area (Auld, 1985). Some 150 subjects were identified as highly anxious on the basis of this measure (i.e., sten score $>6$ ). Next, the 150 students were randomly assigned to an experimental biofeedback intervention group or to a no-intervention group. Thus, extraneous variables were assumed to be equal 
between the two groups. With this in mind, a $t$-test was conducted upon available intelligence scores of the two groups with no significant differences found. All students attended one of three middle schools within a midwestern city.

\section{Procedure}

The subjects in the biofeedback intervention group $(n=72)$ received 12 sessions of biofeedback training. Specifically, there were 6 sessions of thermal training and 6 sessions of electromyographic training. Thermal biofeedback training measures the skin temperature of a child. The child is then taught to raise or lower their skin temperature at will in an effort to increase each student's self control. Electromyograph (EMG) biofeedback monitors the muscle tension of the child by measuring the electrical impulses generated by the muscle (Orton \& Noonberg, 1980). Students received 12 sessions twice weekly over a 12 week period. Thermal training always preceded electromyographic training, the former being less complex and therefore assumed to be less threatening to the subjects. All subjects were trained on site in their respective middle schools by biofeedback technicians. Following the final training session, the Spielberger State-Trait Anxiety Inventory (Spielberger, Gorsuch, \& Lushene, 1970) was administered to the 72 biofeedback intervention subjects and to the 75 no-intervention subjects. This inventory is a 40 -item, self-report measure that has no time limit for completion. It was utilized because of its differentiation between state and trait anxiety.

\section{RESUltS AND Discussion}

To test for significant group differences, group means were subjected to $t$-tests. The biofeedback intervention group attained significantly lower state anxiety scores compared to the no-intervention group $(t=-5.4, p<.001)$. Similarly, the biofeedback intervention subjects also attained significantly lower trait anxiety scores as compared with the nointervention group $(t=-2.25, p<.05)$.

Studies have shown that anxiety contributes to a host of problems concomitantly with interpersonal difficulties. Logically then, anxiety reduction should be accompanied by more effective functioning such as improved memory, enhanced self esteem, and elevated academic performance including better relationships and higher scores on tests (Grazzi, Leone, Frediani, \& Bussone, 1990).

The present study suggests that biofeedback training can effectively and significantly reduce both state and trait anxiety. It also supports the use of two types of biofeedback training (thermal and electromyographic) in combination. The combination of these two techniques provided children with different methods of anxiety reduction. This concurs with clinical findings indicating that the use of more than one biofeedback method is advantageous (e.g., Lamontagne \& Lavalle, 1982).

Prior to the establishment of a biofeedback training intervention program, the psychologist should first determine if the anxiety is environmentally-related. In such situations, anxiety reduction might be best attempted by addressing the system (e.g., family members, teachers) as well as the individual child. If children are anxious, individual biofeedback interventions may need to be considered.

The use of a school-based intervention melds well both with the recent advent of psychological clinics in schools, and with problems within schools themselves. Authors have consistently argued for expanding the psychologist's role to include a focus on interventions (D'Amato \& Rothlisberg, 1992). Schools and other group settings have also been criticized for not offering a curriculum that deals appropriately with the emotional and developmental needs of children (D'Amato \& Dean, 1989). In fact, biofeedback interventions could be used as a component of outcome or standards based education, in that they are behavioral, measurable, practical and can positively influence academic achievement. 
Future research needs to further establish the long-term stability of reduced anxiety levels. Preliminary studies on this stability appear promising (Engel \& Rapoff, 1990). Moreover, sophisticated control groups need be developed to evaluate if reduced anxiety is a clear consequence of biofeedback interventions as well as what combination of biofeedback interventions might be best at reducing anxiety.

With anxiety now being such a debilitating condition, first, at home, then in school, and later in society, effective anxiety reduction interventions for children need to be established (Karnes, Oehler-Stinnett \& Jones, 1985; Last \& Perrin, 1993). For numerous reasons, training in biofeedback may be an appropriate addition to a clinic, hospital, or the school curriculum. Since children are often eager and adept participants, they may well elect to participate. If children, early on, are given the opportunity to participate in experiences which address anxiety, anxiety may be prevented before it becomes a serious concern (Hiebert \& Jaknavorian, 1989).

In the main, mastery and management of certain physiological functions would appear to offer obvious benefits to individual children. Since children are often unable to control their environments, providing them with a method of control over their behavior may equip them with the personal strategies needed to deal with anxiety. Psychologists are in an ideal position to both develop and supervise biofeedback intervention programs in school settings.

\section{REFERENCES}

Auld, F. (1985). IPAT anxiety scale. In D.J. Keyser, \& R.C. Sweetland (Eds.), Test critiques: Vol 2. (pp. 357-362). Kansas City, MO: Test Corporation of America.

Blais, M.R., \& Vallerand, R.J. (1986). Multimodal effects of electromyographic biofeedback: Looking at children's ability to control precompetitive anxiety. Journal of Sport Psychology, 8, 283-303.

Boyle, G. (1987). Commentary: The role of interpersonal psychological variables in academic school learning. Journal of School Psychology, 25, 389-392.

CAtTell, R.B., \& SCheier, I.H. (1976). The IPAT Anxiety Scale. Champaign, IL: Institute for Personality and Ability Testing.

Chang, J., \& Hiebert, B. (1989). Relaxation procedures with children: A review. Medical Psychotherapy, 2, $163-176$.

Culler, R.E., \& Holahan, C.L. (1980). Test anxiety and academic performance: The effects of study related behaviors. Journal of Educational Psychology, 72, 16-20.

D'Amato, R.C., \& DEAN, R.S. (1989). The past, present and future of school psychology in nontraditional settings. In R.C. D'Amato \& R.S. Dean (Eds.), The school psychologist in nontraditional settings: Integrating clients, services and settings (pp, 185-190), Hillsdale, NJ: Erlbaum.

D’Amato, R.C., \& Rothlisberg, B.A. (Eds.) (1992). Psychological perspectives on intervention: A case study approach to prescriptions for change. White Plains, NY: Longman.

ENGEL, J.M., \& RAPOFF, M.A. (1990). Biofeedback assisted relaxation training for adult and pediatric headache disorders. Occupational Therapy Journal of Research, 10, 283-299.

Grazzi, L., Leone, M., Frediani, F., \& Bussone, G. (1990). A therapeutic alternative for tension headache in children: Treatment and follow-up results. Biofeedback and Self Regulation, 15, 1-6.

Gross, T.F., \& MASTEnBrooK M. (1980). Examination of the effects of state anxiety on problem solving efficacy under high and low memory conditions. Journal of Educational Psychology, 72, 605-609.

Hatch, J., Prihoda, T., \& Moore, P. (1992). The application of generalizability theory to surface electromyographic measurements during stress testing: How many measurements are needed? Biofeedback and Self Regulation, 17, 17-39.

Hiebert, B., \& Jaknavorian, A. (1989). School based relaxation: Attempting primary prevention. Canadian Journal of Counseling, 23, 273-287.

Hynd, G.W., \& WiLlis, W.G., (1988). Pediatric neuropsychology. New York: Grune \& Stratton.

Karnes, F.A., Oehler-Stinnett, J.J., \& Jones, G.E. (1985). The relationship between electromyogram level and the children's personality questionnaire as measures of tension in upper elementary gifted students. Perceptual and Motor Skills, 61, 179-182.

KING, N.J., \& Ollendick, T.H. (1989). Children's anxiety and phobic disorders in school settings: Classification, assessment and intervention issues. Review of Educational Research, 59, 431-470. 
KRATOCHWILl, T., \& MoRris, R.J. (1991). The practice of child therapy: Psychoeducational interventions in the school. New York: Pergamon.

LAIL, J.L., \& SCHROEDER, C.S. (1990). Health problems in school aged children. In T.B. Gutkin \& C.R. Reynolds (Eds.), Handbook of school psychology (2nd ed.), (pp. 750-795). New York: Wiley.

Lamontagne, L.A., \& Lavalle, Y. (1982). In J, Boulougouris (Ed.), Learning theory approaches to psychiatry (pp. 245-249). Chicherter: Wiley.

LAST, C.G., \& PERrin, S. (1993). Anxiety disorders in African-American and white children. Journal of Abnormal Child Psychology, 21, 153-164.

MorRIS, R.J., \& MoRRIs, Y.P. (1992). A behavioral approach to intervention. In R.C. D'Amato \& B.A. Rothlisberg (Eds.), Psychological perspectives on intervention: A case study approach to prescriptions for change (pp. 21-47). New York: Longman.

ORTON, D.S., \& NoONBerg, A.R., (1980). Biofeedback: Clinical applications in behavioral medicine. New Jersey: Prentice Hall.

Pliszka, S.R., Hatch, J.P., Borcherding, S.H., \& Rogness, G.A. (1993). Classical conditioning in children with attention deficit hyperactivity disorder (ADHD) and anxiety disorders: A test of Quay's model. Journal of Abnormal Child Psychology, 21, 411-423.

Potashikin, B.D., \& Beckles, N. (1990). Relative efficacy of Ritalin and biofeedback treatments in the management of hyperactivity. Biofeedback and Self Regulation, 15, 305-315.

RoOME, J.R., \& RomNey, D.M. (1985). Reducing anxiety in gifted children by increasing relaxation. Roper Review, 7, 177-179.

SANDOVAl, J. (Ed.). (1988). Crisis counseling, intervention and prevention in the school. Hillsdale, NJ; Erlbaum.

Schalling, D. (1977). The trait-situation interaction and the physiological correlates of behavior. In D. Magnusson \& N.S. Endler (Eds.), Personality at the crossroads: Current issues in interactional psychology (pp. 129141). Hillsdale, NJ: Erlbaum.

SMITH, M.S., \& WOMACK, W.M. (1987). Stress management techniques in childhood and adolescence. Clinical Pediatrics, 41, 581-585.

SonUGa-BARKe, E.J.S., \& BALDING, J. (1993). British parents' beliefs about the causes of three forms of childhood psychological disturbance. Journal of Abnormal Child Psychology, 21, 367-376.

SPIELBERGER, C.D. (1977). State-trait anxiety and interactional psychology. In D. Magnusson \& N.S. Endler (Eds.), Personality at the crossroads: Current issues in interactional psychology (pp. 173-183). Hillsdale, NJ: Erlbaum.

Spielberger, C.D., Gorsuch, R.L., \& LuShene, R.E. (1970). State-trait anxiety inventory manual. Palo Alto: Consulting Psychologist's Press.

WENCK, L.S., \& WoRSTER, V. (1978). Biofeedback and self control. Unpublished manuscript. Ball State University, Educational Psychology, Muncie, IN.

Whitten, J.C., D'Amato, R.C., \& Chittooran, M.M. (1992). A neuropsychological approach to intervention. In R.C. D'Amato \& B.A. Rothlisberg, (Eds.), Psychological perspectives on intervention: A case study approach to prescriptions for change. (pp. 112-136) White Plains, NY: Longman. 